\title{
La excepción dilatoria en el Derecho Procesal (siglos XVI-XVII)
}

\section{The dilatory exception in procedural Law $\left(16^{\text {th }}-17^{\text {th }}\right.$ Centuries)}

\author{
Manuel TORRES AGUILAR \\ Catedrático de Historia del Derecho \\ Universidad de Córdoba \\ mtorres@uco.es
}

Recibido: 4 de marzo de 2013

Aceptado: 6 de junio de 2013

\section{RESUMEN}

En el Derecho real castellano, se establecen determinadas «defensiones» expresamente contempladas en la ley. Tales defensiones o excepciones pueden tener por objeto bien dilatar la causa, prolongándola en el tiempo, pero sin producir su extinción, o bien enervar la acción principal extinguiendo el derecho esgrimido por el actor y dando fin a la causa. El objeto de este estudio es analizar la opinión de la literatura jurídica castellana sobre el particular.

PALABRAS CLAVE: Derecho procesal, excepciones, excepción dilatoria, literatura jurídica.

\begin{abstract}
Certain «defensiones» are expressly contemplated in the royal Castilian law. Such exceptions or defensiones may be intended to cause delay, prolonging the procedure in time, but without causing extinction or weakening of the main action, that would extinguish the right wielded by actor and would therefore end the cause. The purpose of this study is to analyze the opinion of the Spanish legal literature on the subject.
\end{abstract}

KEYWORDS: Procedural Law, exceptions, dilatory exception, legal literature.

\section{RÉSUMÉ}

Dans le droit royale castillan, certaines exceptions ou « defensiones » on été expressément prévues par la loi. Ces exceptions ou defensiones ont pu être destinées bien à provoquer le rétardement de la cause, la prolongant ainsi dans le temps, mais sans provoquer l'extinction, ou bien à l'affaiblissement de l'action principale, étendant le droit exercé par l'acteur et mettant fin à la cause. Le but de cette étude est d'analyser l'opinion de la doctrine espagnole sur le sujet.

MOTS CLÉ : droit procédural, exceptions, exceptions dilatoires, littérature juridique.

\section{ZUSAMMENFASSUNG}

Im kastillisch-königlichen Recht haben sich bestimmte, ausdrücklich im Gesetz vorgesehene «Verteidigungsstrategien» etabliert. Derartige Einreden können darauf abzielen, den Rechtsstreit in die Länge zu ziehen, aber ohne seine Erledigung zu verursachen oder die Hauptverhandlung zu verhindern, um 
somit sogar das Recht des Klägers erlöschen zu lassen bzw. die Sache an sich zu beenden. Das Ziel der vorliegenden Studie ist es, hierzu die Meinung der juristischen Literatur Kastiliens zu analysieren.

SCHLÜSSELWÖRTER: Prozessrecht, Einreden, aufschiebende Einreden, juristisches Schrifttum.

1. Según disponen las normas del Derecho real (Fuero real, Partidas, Nueva Recopilación) a lo largo de este período debidamente comentadas y, en su caso, interpretadas por una doctrina jurídica tan copiosa como especializada, el demandado muy bien puede no contestar a la demanda planteada contra él por el actor. Para ello puede proceder esgrimiendo conforme a Derecho determinadas "defensiones" expresamente contempladas en la ley. Tales defensiones o excepciones pueden tener por objeto bien dilatar la causa, prolongándola en el tiempo, pero sin producir su extinción, o bien enervar la acción principal extinguiendo el derecho esgrimido por el actor y dando fin a la causa. En el primer caso se habla de excepciones dilatorias y en el segundo perentorias.

Esto no quiere decir, sin embargo que junto a aquellas excepciones estrictamente dilatorias, como, por ejemplo, aquella que tiene por objeto neutralizar los efectos de la demanda interpuesta por el acreedor contra el deudor antes del plazo previsto para que se produzca el cumplimiento de la deuda, existan otras que, siendo inicialmente y por su objeto dilatorias, de forma accidental puedan transformarse en perentorias. Tal es el caso de la exclusión o excusión del deudor principal, cuando este último ha satisfecho la deuda contraída con el acreedor demandante, por lo que, satisfecha la deuda, no puede repetir ni contra éste ni contra el fiador del mismo. Tal vez por ello Alonso de Villadiego desde el primer momento habla de una división tripartita, al distinguir entre excepciones dilatorias, perentorias o mixtas. Puesto que respecto de las dos primeras parece no existir contradicción alguna, real ni aparente, en lo que se refiere a la opinión que aquellas les merece a tratadistas, me limitaré a reproducir lo que este último autor nos dice en relación con las que denomina excepciones mixtas:

Las excepciones mixtas se dicen así, porque se pueden proponer en cualquier parte del pleyto, asi antes, como después de la contestación, como son la excepcion de descomunión, y la del dinero no contado: y todas las dichas excepciones perentorias tambien se pueden decir mixtas, porque se juzgan, y pueden proponer, ó 'in vim peremtoriarum', ó 'dilatoriarum', asi antes, como después de la contestación ${ }^{1}$.

Por su parte, Gonzalo Suárez de Paz nos explica que la excepcion es una accion, o la intencion de exclusión. Sin embargo, está plenamente consciente de que esta afirmación y otras relacionadas con el concepto de excepción, entendido en un sentido

\footnotetext{
${ }^{1}$ Alonso de Villadiego, Instrucción politica y práctica judicial, Madrid, 1788, cap. I, n ${ }^{\text {os }} 8$ y 10, p. 9. Del mismo parecer es Juan de Hevia Bolaños, Curia Philipica, Madrid, 1761, Tomo I, apt. 13, n 5, p. 68. cuando se refiere a las excepciones de non numerata dote o non numerata pecunia a las que también califica de excepiones "mixtas", es decir, dilatorias y perentorias.
} 
genérico, no goza de la unanimidad de los tratadistas. Es por ello que, en un intento por conciliar la multitud de opiniones diversas y hasta contradictorias que se daban entre los autores, empieza por adherirse a la opinión, siempre autorizada, de Covarrubias, así como a los máximos representantes de la glosa y el comentario, fundamentalmente de origen italiano. De conformidad con ello nos dirá que

exceptionem proprie esse actionem exclussionem, non vero intentionis ${ }^{2}$.

Discurre el autor que por su naturaleza no se pueden plantear determinados tipos de excepciones. Por ejemplo, la del criminal autor de un robo contra la persona del expoliado. Tampoco se puede perseguir con ello impedir la restitución la restitución de los bienes que han sido arrebatados a la víctima. Y ello porque spoliator inimicus spoliri praesumitur ${ }^{3}$.

Siguiendo a Diego Pérez y su comentario al fundamental texto de la Nueva Recopilación IV, V, 1 admite la existencia de excepciones praejudiciales y perentorias. En su opinión ambas pueden ser planteadas después de la litis contestationem, aunque siempre dentro del término de 20 días como máximo. La insistencia del autor en este último punto se apoya en la idea de que sobrepasar este plazo equivaldría a una mutación de la actuación del demandado, es decir, supondría la no existencia de una excepción sino, más bien, de una verdadera defensa dentro del proceso (non est exceptio sed potius defensio $)^{4}$.

Respecto a la distinción o clasificación de las excepciones Suarez de Paz se adhiere a la corriente general partidaria de distinguir los dos tipos ya conocidos de excepciones, dilatorias y perentorias, aunque no se opone a la opinión de aquellos autores que añaden a estas últimas las "anómalas", también llamadas "mixtas". Con lo cual puede decirse que este autor concreta de este modo dos especies de excepciones: dilatorias, también llamadas por algunos autores "emergentes", y mixtas, estas últimas denominadas igualmente perentorias.

Conviene anticipar que, ya en el proemio al título IV de la Partida III, y como una muestra más del rigor y precisión tanto conceptual como metodológica del texto alfonsino, se contienen unas advertencias que merecen ser recordadas en este momento. Bajo el título general De los jueces, e de las cosas que deuen fazer, e guardar inserta el siguiente comentario que, por lo genérico de su contenido, abarcará una serie de cautelas que, para la buena marcha del proceso, habrán de ser tenidas en cuenta por parte de los jueces, actores y demandados. Tales cautelas se extienden a lo largo del mencionado título IV. Se dice en el citado proemio:

\footnotetext{
${ }^{2}$ Gonzalo Suárez de Paz, Praxis Eclesiastica et Saecularis, Madrid, 1609, aunque utilizo la de Madrid, 1760, I. Tom., I. Pars., Temp. V, n ${ }^{\text {os }}$ 1-7 p. 60.

${ }^{3}$ Ibidem, $\mathrm{n}^{\text {os }} 8-10$, p. 61.

${ }^{4}$ Ibidem, $\mathrm{n}^{\text {os }} 9-11$, p. 61.
} 
Asaz se entiende por las leyes que auemos dichas en los titulos ante deste, como los demandadores deuen ser apercibidos, ante que comiençen sus demandas, en catar todas aquellas cosas, por que mas derechamente las puedan fazer, e començar sus pleytos. E otrosi de los demandados, en que manera deuen responder a las demandas, que les fizieren: porque cada uno dellos faga la carrera que le conuiene, e non fagan a los que han de judgar trabajar en balde.

Seguidamente, debo decir que estos son los términos con los que el citado texto legal contempla la actuación procesal denominada excepción dilatoria, cuya influencia en el desarrollo de los procesos tanto civiles como criminales seria ocioso recordar:

Defiendense los demandados a las vegadas de las demandas que les fazen, poniendo defensiones ante si, que son de tal natura, que aluengan el pleyto, e non lo rematan. E [son] llamadas en latin dilatorias, que quiere tanto decir como alongaderas ${ }^{5}$.

2. Como es lógico no resulta nada complicado encontrar entre los autores de los siglos XVI y XVII una definición de lo que había de entenderse por excepción dilatoria, en contraposición al otro tipo de excepciones procesales que, como las perentorias o declinatorias, constituyen instrumentos procesales de muy frecuente uso entre los demandados. Quizás el concepto o, si se quiere, la definición que parece más clara y, al mismo tiempo, más completa sea la de Juan de Hevia Bolaños. Según este relevante tratadista:

Excepciones dilatorias son las que dilatan, y difieren la Causa, impidiendo su ingresso, y prosecución; pero no la extinguen, acaban, ni rematan del todo ${ }^{6}$.

Evidentemente la claridad con que Hevia nos proporciona una definición de excepción dilatoria, no evita que se haga necesaria la descripción de aquellas actuaciones procesales realizadas o que pueda poner en práctica el demandado para conseguir su objetivo de alargar en su beneficio el proceso. De ahí que, con su acostumbrada nitidez expositiva, complemente lo anteriormente expuesto con la enumeración de aquellos supuestos perfectamente incardinables dentro del concepto anterior:

De lo dicho se sigue ser excepcion dilatoria la incompetencia de jurisdicción, litis pendencia, declinatoria del Juez en la Causa, y todas las demas que a su persona tocaren para excluirle del conocimiento de ella. Siguese asimismo ser excepcion dilatoria la que toca à la persona de la Parte, por no serlo legitima para parecer en Juicio en la Causa, respecto de los defectos, y casos por lo que no lo puede hacer; y lo mismo se entiende de su Procurador. Asimismo... se sigue ser excepcion dilatoria la del incierto, ̀̀ obscuro libelo de la demanda, o pedir antes del tiempo que se debia, ò como no se debia, como esta definido en el Derecho Civil, y Real. Y de aqui se infiere ser excepcion dila-

\footnotetext{
${ }^{5}$ Partidas III, III, 9.

${ }^{6}$ Juan de Hevia Bolaños, Curia Philipica, Tomo I, apt. 13, nº 1, p. 67.
} 
toria la exclusión que se ha de hacer contra el principal, primero que se pida al fiador...Tambien se pueden poner por excepciones dilatorias a excepcion de litis finita, transacción, ò Causa juzgada, que huvo sobre lo que se pide, ò decir, que el Rescripto sobre ello ganado, fue con siniestra relacion, ecubriendo la verdad ... Y lo mismo la excepcion e innumerata, dote, ò pecunia, porque estas excepciones son mixtas, peremptorias y dilatorias, $y$ se pueden poner por tales... ${ }^{8}$.

Es evidente que el citado autor persigue, o al menos lo intenta, la exhaustividad al enumerar las causas en las que el demandado puede plantear una excepción dilatoria. No obsta a esta interpretación el hecho de que se refiera a todas las demas que a su persona tocaren. Por otra parte, un simple examen del texto más arriba recogido de las Partidas nos basta para conocer de primera mano aquellos casos más frecuentes en los que la actuación del demandado quede justificada al plantear este tipo de excepciones. Según las Partidas, los actos conocidos en los medios procesales como "alongaderas" son los siguientes:

... si algund ome fiziesse pleyto con su debdor, que los marauedis, o la cosa que le deuia, non gela pidiesse fasta tiempo, o dia señalado, e después desso gelo demandasse en juicio ante del plazo. O si emplazassen alguno delante de tal Judgador, de cuyo fuero non fuesse, o si la una parte contradixesse la personeria de la otra, mostrando razon, por que non deue ser personero, o diziendo que la personeria que trae, non era complida segund derecho, e porende que non era tenudo de responder a la demanda, que le fazen.

Ahora bien, para que el planteamiento de una excepción pueda ser válido en Derecho y surta los efectos que les son propios es necesario que aquella sea presentada por el demandado dentro de un plazo determinado:

que atales defensiones como estas, o otras semejantes dellas, poniendolas el demandado, antes que responda a la demanda, e aueriguandolas, deuen ser cabidas. Mas si después quel pleyto fuese començado por respuesta, las quisiesse poner alguno ante si, non deuen ser cabidas ${ }^{9}$.

Otra ley anterior del mismo texto normativo, al tiempo que justifica que el deudor demandado se defienda de la reclamación presuntamente injusta hecha por su acreedor demandante, exige que lo haga cumpliendo dos requisitos: que la defensión tenga lugar dentro de plazo y que el que la planteare pruebe la veracidad de lo por él alegado como defensión o excepción dilatoria. Caso contrario el juez podrá interpretar que la

\footnotetext{
${ }^{7}$ A esto se refiere de forma genérica expresamente el Fuero real I, I, X, 5: Que es lo que debe haber el Bozero del pleyto, e que deue ante el juez razonar. Precepto que repiten con mayor número de condiciones y prohibiciones las Partidas III, VI, 7: En que manera deuen los Abogados razonar los pleytos en juicio, en demandado, o en respondiendo.

${ }^{8}$ Ibidem, n ${ }^{\text {os }}$ 2, 3 y 4, p. 67.

${ }^{9}$ Partidas III, III, 9.
} 
actuación del demandado fue maliciosa y pudo tener como fin alargar injustificadamente el pleito en perjuicio de los intereses del acreedor demandante:

Conocen a las vegadas los demandados, lo que les demandan en el juicio. Pero ponen luego defensiones ante si, que han pagado, ofecho aquello que les demandan, o que los demandadores les fizieron pleyto, que nunca gelo demandasen. E porende dezimos, que en tales razones como estas, o en otras semejantes dellas, que deue el Judgador dar plazo al demandado, a que pruebe la defension, que ouiere puesta ante si E si la prouare, deuel dar por quito de la demanda, e fazer que el demandador peche las costas, que ouiesse fecho el demandado en esta razon. E si al plazo que fuere puesto, non pudiere probar la defension, deuel dar por vencido de la demanda. E aun demas desto mandamos, que si el Judgador entendiere, que el demandado maliciosamente puso ante si la defension, para alongar el pleyto, quel faga pechar las costas... que el demandador fizo, andando en aquel pleyto, por razon de tal alongamiento ${ }^{10}$.

Por su parte, la Nueva Recopilación recoge el precepto anterior incorporándole nuevos elementos, tanto para garantizar que se cumple el plazo previsto, como para impedir que su planteamiento por el demandado constituya una argucia tendente a complicar el desarrollo del proceso y alargarlo en perjuicio de la otra parte ${ }^{11}$.

Tal vez por eso Suárez de Paz hace una advertencia de evidente contenido práctico. Considera que si bien por Derecho común el término establecido para plantear las excepciones dilatorias antes de contestar a la demanda podrá ser abreviado a juicio del juez y si las circunstancias procesales lo permiten, en cambio de acuerdo con lo establecido en el Derecho real (Partidas y Nueva Recopilación) el término para exhibirlas en juicio es de nueva días, es decir, justamente el plazo que se ha por la norma para que se produzca la "litis contestata". Este plazo no puede ser abreviado por el juez porque se trata de un término a lege concessus absque ministerio judicis ${ }^{12}$. A fines del siglo XVIII será el Conde de la Cañada quien nos confirme la vigencia de

\footnotetext{
${ }^{10}$ Partidas III, III, 8. Y no solo ha de estar atento el demandado a tener en cuenta todas estas precauciones

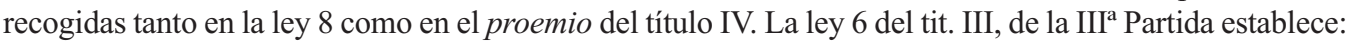
Apercibirse deue el demandado, ante que responda a la demanda quel quieren fazer,que cate el tiempo, en que gela fazen. Ca si fuere dia feriado, non es tenudo de responder en el, sobre demanda que le fagan... E si por aventura fuesse tal dia en que deuiesse responder, déjese fazer dar en escrito, la demanda que quieren mouer contra el, e tomar plazo de tercero dia, en que conseje, e ve todo el recabdo, que tiene por cartas, o por testigos, o por otro derecho, de que se puede ayudar, contra aquello quel demandan. No es este el caso de los contratos que tienen aparejada ejecución, Respecto de los cuales las Ordenanzas Reales de Castilla, III,XI,4 ordenan que contra las obligaciones contractos, compromisos ò sentencias, ù otras cualesquier escripturas que tengar aparejada execucion, que no sea admitida ni recibida por nuestros Juezes ninguna, ni alguna excepcion, ni defensión salvo paga del deudor ... y otras que cita.

${ }^{11}$ Nueva Recopilación IV, III, 1: Que pone quando se han de poner las ecepciones declinatorias, i probarse; $y$ en que termino las excepciones peremptorias, reconvenciones; i como i quando se han de presentar las escrituras con ellas.

${ }^{12}$ Gonzalo Suárez de Paz, Praxis eclesiastica, tomo I, pars. I, temp. V, p. 62, no 17-18.
} 
lo preceptuado en el Derecho regio (especialmente Nueva Recopilación IV, IV, 1 y IV, III,2) y, por tanto, la obligación tanto del juez como de la parte demandada de atenerse a los términos estrictos establecidos:

El demandado tiene el término de nueve días para instruirse de la demanda, y deliberar su contestación empezando à correr y contarse desde el siguiente al de la notificación del traslado; pues está en su arbitrio tomar la demanda, enterarse de ella, y consultar su resolución acerca de confesarla ó contradecirla; y estos nueve días corren por momentos sin interrupción ni descuento de los feriados, porque son continuos y perentorios á fin de no alargar los pleytos con voluntarias ó maliciosas dilaciones ${ }^{13}$.

Puede suceder, sin embargo, que el demandado ignorante de los hechos, o el impedido con causa justa no puedan atenerse al término establecido legalmente. En este caso y siguiendo los pasos de Partidas III,VII,11 (Si aquel que fuere emplazado mostrare escusa derecha por que non vino, que le deue valer) así como Nueva Recopilación IV,V,1 concluye el mismo autor que no les corre el término, ni se consideran rebeldes para caer en la pena de tenerlos por confesos y contestada la demanda. Lo que quiere decir que tienen el beneficio reconocido por la ley de poder presentarse ante el juez en cualquier momento, siempre que justifiquen las razones aducidas. Estas deberán ser de tal naturaleza que les excuse de rebeldía. En consecuencia, conservarán el término, y gozarán de él para responder y contestar, o proponer excepciones dilatorias ... ${ }^{14}$.

En definitiva, como puede colegirse de los textos aludidos, tanto de Partidas como de Nueva Recopilación y de acuerdo con los comentarios realizados por el elemento doctrinal, pueden considerarse causas suficientes para plantear una excepción dilatoria las siguientes: si el acreedor de una cantidad cierta exigiese mediante demanda al deudor el pago de dicha cantidad antes del plazo establecido (contractualmente) entre ambas partes; si el demandante citase a la parte contraria ante un juez incompetente para conocer del caso; si el demandado alegare razones válidas en Derecho para recusar al abogado de la parte contraria por considerar que el poder que aquel tiene de su parte no se ajusta a Derecho; o si su intervención en el proceso se hizo con artimañas de uso forense o ardides de cualquier tipo que merecieren la condena judicial; en los casos de dote o pecunia no numeradas; por hallarse el pleito en situación de litis finita, transacción o cosa juzgada, etc. Simplificando lo dicho y para su más fácil entendimiento todas estas causas podrían ser agrupadas de la siguiente forma: relativas a la persona del juez, a la persona del actor, del reo, por error en la materia, por falta de poder al representante o por defecto de forma.

Suárez de Paz, por su parte, establece una ordenación de las excepciones dilatorias (es decir, aquellas que ... non tamen extingunt negotium) en tres grupos o especies

\footnotetext{
${ }^{13}$ Conde de la Cañada, Instituciones prácticas de los Juicios Civiles, así ordinarios, como extraordinarios, Madrid, 1794, pp. 38-39, nº.

${ }^{14}$ Ibidem, p. $40, \mathrm{n}^{\circ} 9$.
} 
diferentes: qaedam enim Iudicis personam recipiunt; quaedam litigantes personam; alià vero ad totam causam respiciendam sunt adiuvanta. Brevemente diremos que la primera de ellas vienen constituidas por la excepción declinatoria, la excepción de incompetencia y la recusatoria. La segunda, conocidas como excepciones legitimationis personae, engloba los casos del pupilo que realiza actos jurídicos sin la asistencia de su tutor, los del menor de edad que actúa sin conocimiento de su curador o padres y, finalmente el supuesto de la mujer casada que actúa sin licencia marital ${ }^{15}$.

El Conde de la Cañada considera que Paz al prestar atención preferente a la contestación, lo que hizo fue ligándose al tiempo material en que debían proponerse, sin advertir que las leyes establecen la regla de que á la demanda á de seguir necesariamente la contestación, y por limitación ó excepción de esta regla señalan los casos en que los reos tengan y quieren usar de tales excepciones para dilatar ó impedir; y no debe invertirse el orden de establecer en primer lugar la regla, y tratar después de sus limitaciones, como lo observa la buena legislación, y se demuestra en los títulos II, III y IV de la Recopilación ${ }^{16}$.

En cualquiera de estos casos el demandado no tiene obligación de responder a la demanda que debió iniciar el pleito. En definitiva, el citado texto de las Partidas no hace otra cosa que enumerar supuestos concretos que, no solo dan ocasión a plantear una excepción dilatoria, sino que materializa en ellos las cautelas previstas en el proemio del título IV de la Partida III, en el que advierte a los demandantes tener en cuenta todas aquellas cosas que el Derecho exige antes de dar comienzo a un pleito. Sobre todo porque con ello non faga a los que han de juzgar trabajar en balde.

Sin embargo, apostilla el Conde de la Cañada que cuando la contestación a la demanda se hace "llanamente" y de buena fe, de modo que el demandado confiesa la existencia de la obligación que le reclama cumplir el actor, ello impide el progreso del juicio y no dexa mas partes al juez que las de condenarle in continente al pago ó restitucion de la cosa que se le pide concediéndole término competente ${ }^{17}$. Desde luego, esto queda claramente reflejado en Partidas III, III, 7, al disponer que en tal caso de reconocimiento de obligación o deuda por el demandado, debe proceder: otorgando de llano lo que le demandan, si es cierto que verdaderamente lo deue. Ca si lo negasse, e le fuesse después prouado, caeria porende en daño... pechando lo que le demandauan, e demas las costas... Mas quando otorgase luego lo que devia, el Judgador le debe mandar que page lo que conosció, fasta diez días ó á otro plazo mayor, segund entendiere que es quisado, en que lo pueda cumplir.

Pero la misma ley 9 a que nos venimos refiriendo recoge, además, algunas advertencias dirigidas esta vez al demandado para que el planteamiento de una excepción dilatoria pueda tener lugar. En efecto: estas "defensiones" y otras semejantes dellas

\footnotetext{
${ }^{15}$ Gonzalo Suárez de Paz, Praxis Eclesiastica, Tom, I. Pars. I Temp. V, n ${ }^{\text {os }} 12-13$, p. 62.

${ }^{16}$ Conde de la Cañada, Instituciones prácticas de los juicios civiles, p. 41, no 13.

${ }^{17}$ Ibidem, p. 41, n ${ }^{\mathrm{o}} 14$.
} 
deben ser planteadas por el demandado antes de responder a la demanda, de tal forma que si lo hace después que hubiese comenzado el pleito en tal caso no deben ser admitidas. De igual modo el mismo texto legal desliza otra advertencia destinada a tener un dilatadísimo juego en la historia del proceso, tanto civil como criminal. La expresividad con que esta ley recoge la mencionada cautela merece que esta sea recogida textualmente:

Otrosi, dezimos, que si el Judgador entendiere, que el demandado pone a menudo maliciosamente defension ante si, por alongar el pleyto, que puede el Juez, dar un plazo peremptorio al demandado, que ponga todas sus defensiones, ayuntadas en uno, e que las pruebe. E si al plazo que le fuere puesto, non las prouare, o non las pusiere, que después non deue ser oydo. Mas deue el Judgador yr adelante por el pleyto, assi como mandan las leyes deste libro ${ }^{18}$.

De lo que nos habla este texto de las Partidas es de uno de los problemas más conocidos y de mayor persistencia en la administración de justicia de todas las épocas. Sin detenerme en ello, por ser un tema suficientemente conocido, citaré algunos casos concretos. A la petición 45 hecha por los estamentos en las Cortes de Valladolid de 1312 el rey Fernando IV responde a los procuradores asistentes a las mismas en términos que ya antes y mucho tiempo después serán repetidos por sus sucesores ante la insistencia por los representantes de las ciudades:

Otrosi tengo por bien quelos mios alcalles e los mios juezes delas mis villas e los otros offiçiales dela justiçia delos mios logares que ffagan bien e derecha ment la justicia, e que non consientan alongar los pleytos, assi que todo omne quelo ouier mester, pueda alcanzar derecho ${ }^{19}$.

Como recientemente ha sido puesto de relieve por un autor, la normativa contenida en las leyes de Partidas habían tenido el acierto de poner en marcha, o mejor, de acelerar un proceso tendente a que el principio de la sumariedad procesal se transformase en una realidad práctica y, a la vez, cotidiana. Es por ello que tras el espaldarazo contenido en el código de Alfonso X, el Ordenamiento de Segovia de 1347 sguido de muy cerca por el Ordenamiento de Alcalá de Henares de 1348 y pocos años más tarde por el Ordenamiento de Sevilla de 1360 trataron de dar encaje y apoyo legal suficiente para que el acuciante problema del alargamiento de los pleitos en Castilla recibiese el freno a que los abusos que generaban a diario se habían hecho acreedores.

Concretamente, el último de los citados, es decir, el Ordenamiento de Sevilla de 1360, venía justificado, según se hacía constar en la "exposición de motivos" del mismo,

\footnotetext{
${ }^{18}$ Partidas III, III, 9.

${ }^{19}$ Cortes de los Antiguos Reinos de León y de Castilla, publicadas por la Real Academia de la Historia, tomo I, Madrid, 1861, p. 209.
} 
porque la justicia es una de las cosas por que mejor e mas enderezadamente se mantiene el mundo, quando es fecho commo deue, e porque la justicia quiere tanto decir como dar a cada uno su derecho, e porque este derecho se embarga e se aluenga muchas veces por malicias e mentiras que las partes trahen en juicio, poniendo demandas e defensiones non verdaderas e diciendo que los testigos que han para provar que son dellos muy lexos de la tierra... otrosí se aluengan por algunos abogados faziendo razones e escripturas muy luengas... e deteniendo e alongando los pleitos con entencion de levar grandes salarios de las partes; otrosí se aluengan por razón de las apellaciones que las partes fazen maliciosamente de las sentencias que contra ellos dan... ${ }^{20}$.

Por supuesto que estos mismos problemas que tan gravemente afectaban a quienes acudían a los jueces y tribunales de España en busca de justicia, tenían su lógica réplica en los territorios americanos. Aquí, por supuesto, con un lógico añadido de gravedad motivado tanto por la distancia del centro del poder como por la libertad que "de hecho" operaban los funcionarios adscritos a las actividades judiciales (jueces, oidores, alcaldes del crimen, relatores, escribanos abogados, procuradores, etc.).

Como ha expuesto recientemente García Marín, este tipo de denuncias referentes a abusos en la tramitación de los procesos, muchos de ellos derivados de un injustificado alargamiento de los trámites procesales, proliferarán en los escritos de virreyes, visitadores, oidores, corregidores o alcaldes mayores desde mediados del siglo XVI has los últimos momentos de la dominación española en América. Por parte de algunos de éstos se proponía que "los juicios ordinarios seguidos según el orden procesal castellano eran los menos inadecuados para ser de aplicación en los pleitos en que interviniesen indios... Pero también [lo eran] para un buen número de españoles con escasas posibilidades de alterar en su favor la voluntad tanto de jueces como del personal subalterno. Este tipo de procesos ordinarios exigían para su cumplimiento la intervención de una serie de personas... de los que era fácil esperar algún tipo de tropelía al amparo de los formalismos legales y procesales, obviamente en detrimento de los intereses de los litigantes". ${ }^{21}$

A principios del siglo XIX Martínez Marina se refería al mismo tema sin olvidar la perspectiva histórica, dando noticias de las diferentes razones que motivaban el cáncer de la dilación de los pleitos a lo largo de los siglos. Para él no solo eran culpables los procuradores, abogados, relatores, escribanos o jueces, todos ellos en un afán desmedido de sacar del litigio mayores ventajas económicas. También culpaba

\footnotetext{
${ }^{20}$ Francisco Luís Pacheco Caballero, "Sin luenga de pleito e de malicia e sin gran costa", El Dret Comú $i$ Catalunya. Actes del XII Simposi Internacional, Barcelona 26-28 de mai de 2005, Barcelona, 2006, pp. 247-250. Ver también Enrique Gacto Fernández, Sobre la justicia en las fuentes literarias, Murcia 2002, p. 60. Igualmente Ma Paz Alonso Romero, El proceso penal en Castilla (siglos XIII-XVIII), Salamanca, 1982, p. 160 y "El solemne orden de los juicios. La lentitud como problema en la historia del proceso en Castilla", Derecho y proceso, ed. de Juan Damián Moreno, Anuario de la Facultad de Derecho de la Facultad Autónoma de Madrid, nº 5, Madrid, 2001.

${ }^{21}$ José $\mathrm{M}^{\mathrm{a}}$ García Marín, La justicia del rey en Nueva España, Córdoba, 2011, pp. 355-356.
} 
al propio Derecho aplicable en los tribunales y a la escasa prevención que tenían ante estos males de la justicia. Según Martínez Marina:

Es cosa averiguada, que la eterna duración de los pleytos, la confusión de los negocios, la lentitud de los procedimientos, la incertidumbre y perplejidad de las partes acerca del éxito de sus pretensiones, aún las mas justas, dimanaron siempre la infinita multitud de leyes... de las fórmulas, procedimientos, sutilezas y solemnidades judiciales del derecho romano, autorizado en España y trasladado a esta tercera Partida ${ }^{22}$.

Sobre todo esto son de tener en cuenta lo que a propósito de la utilización de excepciones dilatorias, sus efectos, cautelas, límites y plazos, nos dice Hevia Bolaños. Juicios que, en última instancia, no son sino sólidos argumentos compartidos por otros tratadistas de su preferencia, esencialmente Juan Gutiérrez, quien dedicará al asunto toda la Quaestio LII, del lib. I, pp. 118-119 de su Practicarum Quaestionum circa Leges Regias Hispaniae, (Madrid 1598), Diego de Covarrubias que tratará el tema de la recusación judicial en el cap. XXVI, pp. 126-129 de su homónima Practicarum quaestionum (Salamanca 1556) o Gregorio López en algunas de sus glosas a las leyes de Partidas atinentes al tema. Todo ello sin dejar de remitirse a una larga relación de autores anteriores o contemporáneos españoles o italianos.

Según Hevia,

Estas excepciones dilatorias, y que se pueden poner por tales, impiden el ingresso, y prosecución del pleyto, poniendose, y probandose antes de la contestación, y dentro de los nueve dias en que en ella se puede hacer, y no después, ... Y después del dicho termino no se han de admitir por dilatorias, aunque sea con juramento, que de nuevo vinieron à su noticia... ni por via de restitucion de privilegiado, que la tenga, si no es que les resulte grave daño, en cuyo caso las tienen para ponerlas, y probarlas, aunque sea después del dicho termino, y de la contestación, como lo trae el mismo Gutierrez, refiriendo las contrarias opiniones que sobre esto hay... ${ }^{23}$.

Suárez de Paz deja también claro que, por su propia naturaleza, las excepciones dilatorias no pueden plantearse entre los litigantes después de la litis contestationem. Sin embargo, hace especial reserva de lo que sucede en el Derecho Regio aplicable en Castilla. Aquí -advierte- deben plantearse dentro de los nueve días contados desde el fin del último término asignado en la citación para comparecer en juicio y acto seguido responder a la demanda ${ }^{24}$.

Por supuesto, una de las excepciones dilatorias más importantes y frecuentes fue la recusación judicial, también designada como excepción declinatoria. Como acabo de decir, a esta excepción dedica Diego de Covarrubias un capítulo de su famosa

\footnotetext{
${ }^{22}$ Francisco Martínez Marina, Ensayo histórico-crítico sobre la antigua legislación y principales cuerpos legales de los Reynos de León y Castilla, Madrid, 1808, p. 333.

${ }^{23}$ Juan de Hevia Bolaños, Curia Philipica, Tomo I, apt. 13, nº 6, p. 68.

${ }^{24}$ Gonzalo Suárez de Paz, Praxis Eclesiastica, I. Tom., I. Pars., Temp. V, nos 14-16, p. 62.
} 
obra. Precisamente al hilo de algunas de las consideraciones que el célebre catedrático salmantino hace a propósito de ella, Hevia Bolaños nos pone al tanto de una de las cautelas que el demandado ha de tener en mente antes de iniciar cualquier acción o simple escrito ante el juez que piensa recusar. Dice Hevia que Entre todas las excepciones dilatorias, la primera que se ha de poner ha de ser la declinatoria del Juez, porque si se pone otra primero, es visto interpelarle, para que sobre ella pronuncie, y por el consiguiente conferir en Juez no suyo, y prorrogar su jurisdicción, siendo prorrogable, y no de otra manera ${ }^{25}$.

Con este tipo de cautelas lo que está previniendo nuestro tratadista es que, antes de la contestación de la demanda, el demandado debe evitar dirigirse al juez en términos que puedan ser interpretados como aceptación de su jurisdicción. De ahí que tanto la normativa como la doctrina insistan en que la presentación de la excepción declinatoria sea antes de la litis contestata. Con todo, ello puede no ser suficiente ya que el actor podrá hacer uso de artimañas para que, aún sin presentar el reo la declinatoria, realice ciertos actos cuyo significado sea a la postre reconocer que el juez es competente para conocer del caso. El mismo Hevia propone que, para defenderse de este tipo de argucias procesales con efectos negativos para el demandado, este último tiene a su mano una solución de urgencia: que el reo use de contracautela, respondiendo, que viene ante él [el juez] a litigar, salvas sus excepciones... ${ }^{26}$.

El documento («libelo») en el que se haga constar por el demandado que plantea una excepción declinatoria deberá ser conocido por la otra parte, a la que se dará traslado para que ambas partes litigantes puedan probar en sede de la Audiencia sus posiciones respecto de la competencia o incompetencia judicial. Todos estos actos deberán ser realizados de modo sumario, incluido el pronunciamiento, tanto si es expreso como si lo es tácito, sobre el asunto. En cualquier caso el litigio no podrá continuarse, ni, desde luego, sentenciarlo en definitiva. La sentencia que recaiga en estos casos de excepción declinatoria —en los que está en juego la competencia o incompetencia judicial - pronunciada por los oidores de la Audiencia y Consejos declarandose por jueces competentes, no podrá ser suplicada. En este extremo la Nueva Recopilación no deja lugar a dudas al disponer que en la sentencia que dieren los del nuestro Consejo, i el Presidente, i Oidores de nuestras Audiencias, en que se pronunciaren por Jueces, ò por no Jueces, que no aya lugar a suplicacion, ni nulidad, ni otro remedio, ni recurso alguno ${ }^{27}$.

Con referencia a este último texto normativo Valenzuela Velázquez señala que en una sentencia lata per Dominos de Consilio, en la cual se pronunciaron non iudices,

\footnotetext{
${ }^{25}$ Juan de Hevia Bolaños, Curia Philipica, Tomo I, apt. 13, nº 7, p. 68.

${ }^{26}$ Juan de Hevia Bolaños, Curia Philipica, Tomo I, apt. 13, no 8, p. 68. A continuación, en n ${ }^{\circ}$ 9, p. 68 añade: Haviendose de tratar de declinatoria, y otras excepciones, ... siempre en el principio del libelo, antes de tratar otra cosa, se haga protestación de no ser visto atribuir al Juez mas jurisdicción... de la que el Derecho le compete, cuya clausula es util para no ser visto prorrogarsela...

${ }^{27}$ Nueva Recopilación, IV, V, 4. Hevia Bolaños, Curia Philipica, Tomo I, apt. 13, n 10-11, p. 68.
} 
es decir, incompetentes para conocer del caso que se les planteaba y, por tanto, admitiendo el contenido de la excepción declinatoria, no existe posibilidad de suplicación de nulidad de la sentencia, ni a otro recurso o remedio de los establecidos por el Derecho Regio ${ }^{28}$. La ley recopilada IV, V, 4 es también interpretada de igual forma por Juan Bautista Larrea quien justifica la negación de cualquier otro recurso contra la sentencia de aquellos tribunales superiores en la alta autoridad que ostentan y la integridad atribuida a sus jueces. En cambio si se admite la suplicación cuando se trata de jueces de inferior categoría, a los cuales -según Valenzuela- no se les atribuye tanta autoridad ni tienen la alta consideración que merecen los jueces superiores de las Audiencias y Consejo ${ }^{29}$.

3. Recogíamos un poco más arriba ciertas palabras de Hevia Bolaños en las que consideraba como causa de excepción dilatoria del proceso la excusión o exclusión que ha de hacerse en primer término del deudor principal, antes de requerir del fiador de éste la satisfacción de la deuda contraída en su momento por aquel. En este sentido la excusión ha de ser entendida como requisito previo a todo proceso contra el deudor. En tal sentido los bienes del fiador tienen una consideración jurídico-procesal subsidiaria, de forma que solo puede procederse contra ellos cuando los bienes del demandado y deudor principal no existan o no sean suficientes para satisfacer el montante de la deuda.

Como de costumbre el citado autor se cuida de que cada una de sus afirmaciones quede respaldada por la opinión concordante de otros tratadistas, anteriores o coetáneos, caracterizados por su solvencia científica. Uno de ellos es Antonio Gómez, quien a propósito de la exclusión del deudor principal y la responsabilidad que subsidiariamente debiera corresponder al fiador solidario había realizado una serie de consideraciones que, por su enjundia, merecen ser destacadas. Sobre todo porque las interminables interrogantes a que aquel suele someter cualquier cuestión jurídica que aborde, además de tener origen en lo más relevante del mos italicus constituyen verdaderos cimientos en el hilo argumental de la doctrina posterior. En el caso que ahora veremos he podido constatarlo en otro tratadista tan representativo de la scientia iuris de su tiempo como Salgado de Somoza ${ }^{30}$.

Se pregunta Antonio Gómez sobre el supuesto de si el fiador puede ser llamado a satisfacer la deuda al acreedor antes de que lo sea el deudor principal. En principio

\footnotetext{
${ }^{28}$ Juan Bautista Valenzuela Velázquez, Consiliorum sive responsorum iuris, Liber Primus, Madrid, 1653, Cons. LXX, n 101, p. 523.

${ }^{29}$ Juan Bautista Larrea, Novarum Decisionum Granatensium, Pars. II, Lugduni, 1658, Decisio C, $\mathrm{n}^{\text {os }} 2$ y 4, p. 238. La ley recopilada IV, V, 4 ha de ser puesta en relación con la IV, XVIII, 3, que dispone lo que sigue: establecemos que de las sentencias interlocutorias no aya alzada, i que los Juzgadores no la otorguen, ni la den, salvo si las sentencias interlocutorias fueren dadas sobre defension peremptoria... ${ }^{30}$ Francisco Salgado de Somoza, Labyrinthus creditorum concurrentium, Venetiis, 1701, ver Part. I, cap. XXIII, pp. 137-144.
} 
puede decirse que su respuesta no deja margen para la duda, ya que advierte que si se tiene en cuenta lo que sobre el asunto preceptuaba el Derecho antiguo, la respuesta ha de ser afirmativa: el fiador sí podía ser requerido con anterioridad al deudor principal. Sin embargo, la solución es distinta conforme al Derecho presente. La opinión entre los Doctores (esencialmente comentaristas tanto antiguos como contemporáneos y preferentemente italianos) a los que acude en apoyo de sus palabras considera mayoritariamente que, conforme al nuevo Derecho (de jure novo) esto no puede hacerse hasta que no se haga excusión de los bienes del deudor principal. En el caso de que este último no sea solvente es cuando el acreedor puede dirigirse contra el fiador. No obstante, se exceptúa el supuesto de ausencia del deudor principal cuando esta se produce fuera del territorio sobre la que se extiende la jurisdicción judicial. Ante la dificultad que pueda presentarse de llamarle para cumplir con su obligación, el acreedor demandante puede requerir al fiador en primer lugar ${ }^{31}$.

Sin embargo, la anterior afirmación tiene excepciones que limitan seriamente su aplicación en la práctica. En primer lugar, considerando que lo anterior se entiende como un beneficio que la ley concede al deudor principal demandado, beneficio que desaparece si este renuncia al mismo. Segundo, cuando es notorio que el deudor principal no es solvente, en cuyo caso el fiador será llamado a satisfacer la deuda, aún sin haberse producido excusión de los bienes del deudor principal. Tercero, cuando el fiador que ha sido requerido opone una excepción de excusión. Caso contrario, si no opusiese esta excepción, el juicio es válido y, por tanto, también el proceso, de forma que legítimamente puede ser condenado, ya que dicha excepción no produce efectos contra la sustancia de la acción y, consiguientemente, de la obligación que le corresponde de satisfacer la deuda subsidiariamente, sino solo respecto del orden de proceder. Por lo tanto, el fiador debe oponerse ante litem contestatam, puesto que se trata de una "excepción dilatoria". Aún así, no por ello se anula el proceso ${ }^{32}$.

Cuarto límite, cuando el fiador es banquero (publicus campsor), porque entonces no disfruta del beneficio de la excusión. La razón de ello es la utilidad pública que se deriva de su actividad y la confianza máxima que entre las partes debe existir, dado que ordinariamente es necesario acudir a solicitar el servicio de aquellos. En quinto lugar, cuando el deudor principal y demandado pueda ser requerido fácilmente por el acreedor para que cumpla su obligación de devolver lo adeudado. Ahora bien, lo contrario sucede cuando si por razones personales, circunstancias de lugar o por causa de privilegio aquel no pueda ser requerido fácilmente. En tales casos el fiador puede ser requerido en su lugar y, por tanto, antes de que lo sea el deudor principal. De todo esto se deduce también que existiendo alguna otra razón causante de graves complicaciones jurídico-procesales, como es el caso de deudor pendenciero y amante de los litigios y que no acostumbra a pagar sus deudas sin mediar litigio, en tales casos el

\footnotetext{
${ }^{31}$ Antonio Gómez, Variae resoluciones iuris civiles, Lugduni, 1735, tomo II, cap. XIII, nº 14, p. 262.

${ }^{32}$ Ibidem, p. 262.
} 
fiador también puede ser llamado antes que el deudor principal. Ahora bien, esta última limitación solo procede cuando esta peculiaridad del deudor sobreviniese después de la celebración del contrato origen de la deuda. La solución será diferente si tales cualidades eran conocidas al tiempo de celebrar dicho contrato por el acreedor, en cuyo caso será a este último a quien deba imputarse la culpa (sibi imputandum videtur), ya que a pesar de conocer las circunstancias, sin embargo celebró el contrato. Caso similar es cuando el deudor es solvente y tiene bienes suficientes para satisfacer la deuda, pero solo se puede actuar contra él con grandes dificultades y exigiendo un proceso largo y complicado. En tales circunstancias se presume que el deudor principal no es solvente y el acreedor puede dirigirse contra el fiador ${ }^{33}$.

Era de suponer que Salgado de Somoza, en su muy concienzudo Labyrinthus creditorum abordase una cuestión como esta. Sin duda, su contenido y razón de ser entran directamente en la materia que el libro aborda en sus dos volúmenes con la profusión argumental de los tratados dedicados a una materia específica. A nosotros nos interesa en este momento puesto que si hay una materia que se preste a controversias y disquisiciones entre los autores es precisamente esta relativa a la excepción dilatoria por excusión de los bienes del deudor principal y, por tanto, a la situación de este y del fiador ante el demandante, así como a las múltiples variantes que pueden darse en orden a la preferencia por los bienes de uno u otro, en función de determinadas circunstancias.

Como no considero necesario entrar a fondo en toda la problemática que esto plantea a quien se acerca a ella con mirada puramente indagatoria, me limitaré a enumerar algunos extremos a los que Somoza presta especial atención, siempre partiendo de la base que el complejo mundo de los créditos (el labyrinthus somociano) no es nuestro objetivo en este momento. Sí mencionaré algunos extremos, estrechamente relacionados con nuestro tema, sobre los que la erudición somociana se manifiesta de forma clara. Como punto de partida y en total coincidencia con la generalidad del elemento doctrinal, el mencionado autor declara lo siguiente:

Deinde quia jure cautum est, ne fieijussor possit conveniri ante debitorem principalem, nisi fiat prius excussio in bonis ejusdem. Y no solo eso sino que además y como una muestra más de la cautela con la que ha de procederse judicialmente en estos casos, siempre debe preceder sentencia judicial declaratoria de la existencia de excusión de los bienes del deudor principal, antes de proceder judicialmente contra los bienes del fiador o fiadores. Ello no impide que el mismo Somoza advierta que hay autores que no consideran necesarios tales preámbulos para decretar la excusión. Para quienes opinan de este modo basta con que, una vez iniciada la ejecución contra los bienes del fiador, quede constancia ante el juez de la insolvencia del deudor principal y principal obligado a responder con sus bienes. Finalmente, el autor destaca dos principios que necesariamente deben acompañar al expuesto un poco más arriba:

${ }^{33}$ Ibidem, p. 262. 
uno es que la excusión constituye solo una excepción dilatoria y necesariamente ha de ser propuesta antes de la litis contestatio. La otra es que conforme a lo dispuesto en el Derecho real (cita Ordenanzas reales de Castilla III, 8,1 y Nueva Recopilación IV,5,1) la excepción dilatoria de excusión debe plantearse dentro de 9 días y no de 20 días como sostienen algunos ${ }^{34}$.

En cuanto a los puntos principales que hemos de destacar en las consideraciones insertas en la obra de Salgado de Somoza destacaré estos:

$1^{\circ}$ La excusión de los bienes del deudor principal y demandado, hecha ante juez competente a instancia de uno de los acreedores demandantes, no impide que los otros acreedores que puedan existir se dirijan contra los otros fiadores ${ }^{35}$.

$2^{\circ}$ Puede acudirse directamente al fiador cuando consta notoriamente que el deudor principal carece de solvencia. La pregunta que ha hacerse en este punto es ¿cuándo sucede esto? Según el citado autor en estos casos, entre otros:

a) cuando exista pública fama de su insolvencia y que esta quede atestiguada por declaración de los vecinos del deudor, así como que dicha fama pública transmita el convencimiento de que el deudor principal no puede tener más bienes en el futuro.

b) cuando se produzca juramento solemne del deudor de que no le quedan más bienes con los que satisfacer su deuda y que esta decisión sea atestiguada por su esposa, familia y vecinos de aquel.

c) cuando sea el propio fiador el que en juicio ante juez competente confiese que el deudor principal es insolvente.

d) si son ministros públicos los que, tras ser enviados por la autoridad judicial a investigar sobre la solvencia del deudor demandado, dictaminen bien la inexistencia de bienes, bien su existencia pero en cantidad tal que se considere insuficiente (nulla vel exigua $)^{36}$.

\footnotetext{
${ }^{34}$ Francisco Salgado de Somoza, Labyrinthus creditorum, Parte I, cap. XXIII, nos 41, p. 140, 45, p. 141 y 48, p. 141.

${ }^{35}$ Ibidem, no 32, p. 140.

${ }^{36}$ Ibidem, no 33 , p. 140.
} 